\title{
MAP3K1 Expression is Associated With Progression and Poor Prognosis of Hormone Receptor-Positive, HER2-Negative Early-Stage Breast Cancer
}

\author{
Sung-Hsin Kuo \\ National Taiwan University Hospital https://orcid.org/0000-0003-0054-887X \\ Ming-Feng Wei \\ National Taiwan University Hospital \\ Yi-Hsuan Lee \\ National Taiwan University Hospital \\ Wen-Chi Yang \\ National Taiwan University Hospital \\ Shi-Yi Yang \\ National Taiwan University Hospital \\ Jui-Chueh Lin \\ National Taiwan University Hospital \\ Chiun-Sheng Huang ( $\nabla$ huangcs@ntu.edu.tw)
}

Research

Keywords: MAP3K1, Breast Cancer, hormone receptor-positive, NF-kB, prognosis

Posted Date: August 6th, 2020

DOI: https://doi.org/10.21203/rs.3.rs-53956/v1

License: (1) (i) This work is licensed under a Creative Commons Attribution 4.0 International License. Read Full License 


\section{Abstract}

Background: MAP3K1 (Mitogen-Activated Protein Kinase Kinase Kinase 1) participates in the MAPK signal transduction pathway, responding to a number of mitogenic and metabolic stimuli, which may be related to breast cancer susceptibility and progression. In this study, we assessed whether overexpression of MAP3K1 promotes proliferation, migration, and invasion of breast cancer cells, and thus, affects the prognosis of hormone receptor (HR)-positive, human epidermal growth factor receptor 2 (HER2)-negative early-stage breast cancer.

Methods: Two HR-positive, HER2-negative breast cancer cell lines (MCF7 and T-47D), both overexpressing MAP3K1, were transfected with MAP3K1 short hairpin RNA plasmids (shMAP3K1) and their proliferation, migration, and invasion were examined. We assessed whether shMAP3K1 affects the cell cycle and levels of downstream signaling molecules, such as ERK and NF-KB, as well as sensitizes cells in both cell lines to chemotherapeutic and hormonal agents. A total of 161 patients with HR-positive, HER2-negative T1-T2 breast cancer and 0 to 3 nodal metastases were included. The expression of MAP3K1 and phospho (p)ERK proteins was assessed by immunohistochemistry.

Results: In both cell lines (MCF7 and T-47D), shMAP3K1 significantly reduced cell growth, migration, and invasion by downregulating MMP-9 and blocking the G2/M phase of the cell cycle and its regulatory molecule cyclin B1. Besides, shMAP3K1 downregulated ERK- and NF-KB-dependent gene transcription, and enhanced sensitivities of both cell lines to doxorubicin, docetaxel, and tamoxifen. Patients with MAP3K1 overexpression exhibited significantly poor 9-year disease-free survival (DFS; $72.6 \%$ vs. $88.5 \%, p$ $=0.022$ ) and overall survival (OS; $83.8 \%$ vs. $96.2 \%, p=0.012)$ relative to those without MAP3K1 overexpression. Furthermore, the $p$-ERK expression was significantly associated with MAP3K1 expression $(p<0.001)$ and correlated with a poor 9 -year DFS $(p=0.033)$ and OS $(p=0.023)$.

Conclusions: Our results indicate that overexpression of MAP3K1 plays a major role in poor prognosis of HR-positive, HER2-negative early-stage breast cancer.

\section{Background}

Breast cancer is the most common cancer in women worldwide [1]. In Taiwan, there has been a continuous rise in the incidence of breast cancer [2]. Based on gene expression profiles, breast cancers are classified into different molecular subtypes [3, 4]. Using immunohistochemistry (IHC) to assess the expression patterns of estrogen receptor (ER), progesterone receptor (PR), and human epidermal growth factor receptor 2 (HER2) and using fluorescence in situ hybridization (FISH) technique to assess the amplification of HER2 encoding gene in HER2 IHC (score: 2+) breast cancer, its subtypes can be categorized as follows according to the 2017 St. Gallen Consensus: HR-positive and HER2-negative; HRpositive and HER2-positive, HR-negative and HER2-positive, and triple-negative [5, 6]. Systemic adjuvant chemotherapy is routinely administered for providing the long-term benefits of decreasing recurrence and metastases and prolonging survival outcomes in patients with HER2-enriched or triple-negative subtypes 
of breast cancer [6-9]. For both HR2-positive and HER2-negative patients, systemic adjuvant chemotherapy and endocrine treatment are routinely administered for those with high-risk factors, such as high-grade, larger tumor size, and positive axillary lymph nodes (LNs), whereas endocrine treatments are dispensed for those without high-risk factors [6-9].

In addition to clinicopathological features, several multiple gene assays, including MammaPrint ${ }^{\circledR}$, Oncotype DX $\circledast$, PAM-50 (Prosigna ${ }^{\circledR}$ ), and EndoPredict ${ }^{\circledR}$ have been demonstrated to predict the survival outcomes of patients with HR-positive, HER2-negative, and LN-negative breast cancer to help physicians and patients in opting either adjuvant chemotherapy combined with endocrine therapy or endocrine therapy alone [10-13]. Considering that certain low-risk and high-risk patients still develop local recurrence and distant metastases despite receiving endocrine treatment or chemotherapy followed by endocrine therapy, respectively, the identification of novel genes that can act as alternative prognostic markers as well as targeted genes for HR-positive and HER2-negative patients is warranted.

Genome-wide association studies (GWAS) have identified several single nucleotide polymorphisms (SNPs), such as MAP3K1 (Mitogen-Activated Protein Kinase Kinase Kinase 1) rs889312, associated with breast cancer risk [14-16]. We recently reported that MAP3K1 rs889312 is closely associated with poor disease-free survival (DFS) and overall survival (OS) in early-stage HR-positive breast cancer [17]. MAP3K1, also named as MEKK1 (MEK kinase 1), is a 196-kDa serine-threonine kinase and a member of the MAP3K family and the Ser/Thr protein kinase superfamily [18]. Growing evidence suggests that MAP3K1 participates in the MAPK signal transduction pathway, in response to several mitogenic and metabolic stimuli, including estrogen, which activates JNK1/2 (also known as MAPK8/9), extracellularsignal-regulated kinase (ERK)1/2, or NF-KB $[19,20]$. The upregulation of the aforementioned molecules may promote cell survival and the development of HR-positive, HER2-negative breast cancer [20]. Besides, previous studies have demonstrated that MAPKs and MAPK phosphatase-1 (MKP-1) may be involved in resistance against drugs, including tamoxifen and other chemotherapeutic agents [21, 22].

In a study aimed at identifying somatic copy number changes and mutations in the exons of proteincoding genes in 100 breast cancer tumors, Stephens et al. identified several new cancer-related genes, including AKT2, ARID1B, CASP8, CDKN1B, MAP3K1, MAP3K13, NCOR1, SMARCD1, and TBX, which may be involved in the tumorigenesis of breast cancer [23]. Among these driver mutations, somatic mutations of MAP3K1 are observed in $6 \%$ of breast cancers, predominantly in ER-positive breast cancer [23]. Furthermore, during the analyses of molecular heterogeneity of primary breast cancers through comprehensive molecular portraits, the authors showed that mutations of MAP3K1 are enriched in the HR-positive and HER2-negative breast cancer [24].

Based on aforementioned evidences [19-24], we hypothesized that MAP3K1 can mediate the cell proliferation of HR-positive, HER2-negative breast cancer cells, and is possibly related to the resistance against the adjuvant tamoxifen and other chemotherapeutic agents, and thus, contributes to the early recurrence and metastasis of early-stage HR-positive, HER2-negative breast cancer. To prove this hypothesis, we investigated whether downregulation of MAP3K1 could inhibit cell proliferation, migration, 
and invasion, and affect ERK1/2 and NF-KB activity in the in vitro HR-positive, HER2-negative breast cancer cell lines. To further elucidate the biological functions of MAP3K1, we assessed the relationship between MAP3K1 expression in tumor cells and clinical outcomes in patients with early-stage HRpositive, HER2-negative breast cancers. We also assessed whether the downstream effector molecule of MAP3K1, p-ERK, correlated with the expression of MAP3K1 and the clinical outcome of the same group of tumors.

\section{Materials And Methods}

\section{Cell lines, lentivirus production, and transduction}

For the study, we used human HR-positive, HER2-negative breast cancer cell lines, MCF7 (ATCC ${ }^{\circledR}$ HTB$22^{\text {TII }}$ ) and T-47D (ATCC $®$ HTB-133 ${ }^{\text {TM }}$ ), to assess whether the inhibition of MAP3K1 can affect cell proliferation, cell migration, cell cycle, sensitivity to drugs, and NF-KB activity. These two breast cancer cell lines were cultured in either Eagle's minimum essential medium (ATCC ${ }^{\circledR} 30-2003^{\text {tm }}$ for MCF7) or RPMI1640 medium (ATCC ${ }^{\circledR} 30-2001^{\text {tw }}$ for T-47D) supplemented with $10 \%$ fetal bovine serum (FBS; Hyclone, USA), penicillin, and streptomycin (Flow Labs, Rockville, MD, USA). The cells were cultured in an incubator in a humidified atmosphere containing $5 \% \mathrm{CO}_{2}$ at $37^{\circ} \mathrm{C}$.

The short hairpin RNA (shRNA)-expression vectors and MAP3K1 shRNA constructs were obtained from the National RNAi Core Facility (Taipei, Taiwan). For lentivirus packaging, psPAX2, pMD2.G, and shRNAexpression vectors were co-transfected into 293T cells. The pGIPZ vector, containing a TurboGFP cassette, was used as a scrambled control and a tool for determining viral titer. The supernatant was harvested at $48 \mathrm{~h}$ after transfection, and then the lentiviral particles in supernatant were concentrated with PEG-it ${ }^{\mathrm{TM}}$ Virus Precipitation Solution (System Biosciences, CA, USA). We determined the titers of lentivirus by infecting $293 \mathrm{~T}$ cells with varying concentrations of pGIPZ lentivirus. TurboGFP expression was assessed by flow cytometry, and the lentivirus titer was approximately $1 \times 10^{7}$ infectious units per $\mathrm{mL}$ (IFU/mL). The breast cancer cell lines, MCF7 and T-47D, were infected with virus at a multiplicity of infection (MOI) of 5 . At $24 \mathrm{~h}$ after infection, these infected cells were screened with $2 \mu \mathrm{g} / \mathrm{mL}$ puromycin (InvivoGen, ant-pr-1).

Total RNAs were isolated from each cell subclone (control cells, scrambled cells, and cells transfected with shMAP3K1 using RNeasy Mini Kit (\#74106,Qiagen, Hilden, Germany). Reverse transcription reaction was performed using the Maxima first strand cDNA Synthesis Kit for real-time quantitative PCR (RT-qPCR; \#K1641; Thermo Fisher Scientific, Waltham, MA, USA). Subsequently, the expression of MAP3K1 was quantified using the KAPA SYBR FAST RT-qPCR kit (07959435001; Kapa Biosystems, Woburn, MA, USA) on Applied Biosystems StepOne and StepOnePlus Real-Time PCR Systems (Applied Biosystems; Thermo Fisher Scientific) and the gene expression was normalized against the $\beta$-actin mRNA level. The primers of MAP3K1 used for the RT-qPCR analysis were as follows: 5'-AGGTCGCACAGTGAAATCAG-3' (forward), 5'GTTTCCTCAGGGCTATATGGTG-3' (reverse). The reactions were performed in triplicates. 
Cell proliferation, viability, migration, and invasion assay

The detailed information of cell proliferation, viability, migration, and invasion assay are listed in the Supplementary methods [25].

\section{Cell cycle analysis, apotposis analysis, luciferase assay, and immunoblotting analysis}

The detailed information of cell cycle analysis, apoptosis analysis, luciferase assay, and immunoblotting assay are listed in the Supplementary methods [26-30].

\section{Characteristics, treatments, and tissue samples of HR-positive, HER2-negative early breast cancer patients}

Patients diagnosed with stage I or II (AJCC 2007) HR-positive, HER2-negative early breast cancers at the National Taiwan University Hospital between January 1, 1994, and June 30, 2006, were enrolled for the study. Patients were considered HR-positive if the percentage of ER- or PR-positive epithelial cells was $\geq$ $1 \%[6,17]$. HER2 expression was measured using the universal iView-Dab detection kit. Scores of 0 and $1+$ were considered negative, and a score of $3+$ was considered positive. Gene amplification through FISH-based PathVysion assay (Vysis Inc., Des Plaines, IL, USA) was performed for tumors with a score of $2+$. For the HER2 gene: chromosome 17 ratio of $\geq 2.0$, tumors were considered positive based on the American Society of Clinical Oncology guidelines [31]. Tumors were considered HER2-positive for an IHC score of $3+$ or $2+$, determined through FISH-based gene amplification.

Pathological and clinical information about treatment (including type of surgery, receipt or non-receipt of adjuvant systemic therapy, and type and dose of adjuvant systemic therapy) and follow-up information (including recurrence and distant metastasis) were obtained from pathology reports and clinical records. Patients with high-risk factors, such as grade III cancers, large tumors, and LN positivity (N1), received standard adjuvant chemotherapy, such as CMF (cyclophosphamide, methotrexate, fluorouracil), CEF (cyclophosphamide, epirubin, fluorouracil), CAF (cyclophosphamide, adriamycin [doxorubicin], and fluorouracil), AC/EC, or AC/EC followed by paclitaxel/docetaxel regimens as defined in our previous study [8]. All enrolled patients received adjuvant hormonal therapy, with drugs such as tamoxifen [8]. Adjuvant radiotherapy was administered to all patients after breast conservation surgery [8]. After surgery and adjuvant therapy, the patients were regularly followed-up in our clinic. If patients were lost during followup, information on their disease status and survival was obtained from the patients' charts, hospital cancer registry records, and the National Death Registry.

\section{Immunohistochemistry analysis}

The immunohistochemistry staining for MAP3K1 (clone 256, Abgent, San Diego, CA, USA) [28] and p-ERK [30] were performed on paraffin-embedded sections of surgical specimens using an indirect immunoperoxidase method, according to manufacturer's instructions. To confirm the specificity of MAP3K1, staining was performed on paraffin-embedded sections in the absence of the first, the second, or both the primary antibodies as negative controls. All sections were observed under a light microscope. 
The percentages of MAP3K1-positive cells (tumor cells with readily visible brown staining distinctly marking the tumor cell nucleus and/or cytoplasm) were averaged to yield an immunohistological score ranging from 0 to $100 \%$. The results were classified into two groups according to the intensity and extent of staining: in the MAP3K1-negative group, either no staining was present (staining intensity score: 0 ) or mild immunostaining or positive staining was detected in $<20 \%$ of the cells (staining intensity score: 1 ), and in the MAP3K1-positive group, moderate or strong immunostaining was present in $20-40 \%$ (staining intensity score: 2 ) or more than $40 \%$ of the cells (staining intensity score: 3 ). For the p-ERK marker, positive expression was defined as positive nuclear staining in $20 \%$ of tumor cells $(20-40 \%$, score $=2$; $>40 \%$, score $=3$ ), whereas p-ERK-negative (score $=0$ ), focally positive tumor, or tumor cells with positive p-ERK staining $<20 \%$ (score $=1$ ) was defined as negative, as previously described [32].

\section{Statistical analysis}

In vitro experiments of the proliferation, migration, invasion, cell cycle, apoptosis assay, and luciferase assay, were repeated at least three times; the data of aforementioned assays were presented as the mean \pm standard deviation (SD). The $p$ values of the aforementioned experiments were determined using the student's $t$ test, and statistical significance was defined for a $p$ value $<0.05$. The association between MAP3K1 and p-ERK was analyzed by Spearman's correlation.

For breast cancer patients, follow-up data available on December 31, 2011, were analyzed. DFS was measured from the date of the first surgery for breast cancer to local recurrence, distant recurrence, or death from any cause; OS was measured from the date of the first surgery to the date of death from any cause or the last follow-up date [33]. The DFS and OS were calculated using the Kaplan-Meier method, and the survival curves were compared using the log-rank test. The clinical characteristics were compared using the chi-square test and Fisher's exact tests. $P<0.05$ was considered statistically significant.

\section{Results}

\section{Downregulation of MAP3K1 attenuates cellular proliferation, migration, and invasion of HR-positive, HER2-negative breast cancer cell lines}

As shown in Supplemental Fig. S1 (shMAP3K1-targeted mRNA sequences) and Supplemental Fig. S2 (shMAP3K1-targeted amino acid sequences), we assessed the efficiencies of shMAP3K1-mediated inhibition in both MCF7 and T-47D cells. For that, we assessed mRNA levels of MAP3K1 in control MCF7 and T-47D cells, and the cells transfected with shMAP3K1 using RT-qPCR. We found that mRNA expression levels of MAP3K1 were significantly downregulated in shMAP3K1-transfected MCF7 cells and shMAP3K1-transfected T-47D cells when compared with scrambled MCF7 cells and scrambled T-47D cells, respectively (Supplemental Fig. S3). To approve the specificity of MAP3K1, we used immunofluorescence, immunohistochemical analysis, and western blotting to detect MAP3K1 expression in control MCF7 and control T-47D cells (primary antibody alone, secondary antibody alone, and combination of primary and secondary antibodies), and in shMAP3K1-transfected MCF7 cells and in 
shMAP3K1-transfected T-47D cells (combination of primary and secondary antibodies). The results are illustrated in Supplemental Fig. S3.

These breast cancer cell lines expressing higher levels of MAP3K1 were transfected with shMAP3K1 to downregulate the MAP3K1 protein expression (Fig. 1a). When compared with the scrambled group, shMAP3K treatment significantly reduced the expression level of MAP3K 1 by $84 \%$ in MCF7 cells $(p<$ 0.001 ), and by $75 \%$ in T-47D cells $(p<0.001)$ (Fig. 1a). Proliferation assay showed that the downregulation of MAP3K1 decreased cell number in both breast cancer cell lines (Fig. 1 b ). The cell number was significantly inhibited at Day 3, Day 5, and Day 7 of shMAP3K1-transfected MCF7 and T-47D cells. The results of the migration assay showed that the number of migrated cells was reduced by $48.1 \%$ in shMAP3K1-transfected MCF7 and by $82.3 \%$ in shMAP3K1-transfected T-47D cells when compared with scramble-transfected MCF7 and T-47D cells (Fig. 1c). The results of the invasion assay showed that the number of invaded cells was reduced by $73.7 \%$ in MCF7 cells and by $63.1 \%$ in T-47D cells when compared with scrambled MCF7 and T-47D cells (Fig. 1d). These findings indicated that inhibition of MAP3K1 suppressed cell number, cell migration, and cell invasion in these two HR-positive, HER2negative breast cancer cell lines.

\section{Downregulation of MAP3K1 induces G2/M phase arrest and apoptosis and enhances drug sensitivity in HR-positive, HER2-negative breast cancer cell lines}

Hu et al. reported that transfection with MAP3K1 small interfering RNA leads to the downregulation of expression of $\mathrm{CDC} 25 \mathrm{C}$ and cyclin $\mathrm{B} 1$ (key molecules for $\mathrm{G} 2 / \mathrm{M}$ transition during the cell cycle) in MCF7 cells and MCF-12F cells (normal mammary epithelial cell line) [34]. In this study, we sought to assess whether shMAP3K1 could inhibit the cell number in both breast cancer cell lines by blocking programmed G2/M phase and downregulating cyclin B1.

After $48 \mathrm{~h}$, we determined the distribution of the cell cycle phases in each cell line. As shown in Fig. $\mathbf{2 a}$, in shMAP3K1-transfected MCF7 cells, there was a significant increase in the number of cells in the G2/M phase of cell cycle, and concomitantly, a significant decrease in the number of cells in the G0/G1 phase was observed. On the contrary, in T-47D cells, shMAP3K1 treatment led to an arrest of a significant number of cells in the G2/M phase of cell cycle, and there was a significant decrease in the number of cells in the $S$ phase. These findings indicated that shMAP3K1 blocked cell cycle progression through the G2/M phase. Annexin $V$ staining revealed that shMAP3K1 treatment resulted in increased apoptotic events (early and late apoptosis level) in both MCF7 cells $(16.34 \% \pm 0.77 \%$ vs. $1.84 \%$ $\pm 0.42 \%, p=0.000633)$ and T-47D cells $(13.68 \% \pm 0.31 \%$ vs. $4.87 \% \pm 0.16 \%, p=0.0000517)$ when compared with scrambled MCF7 and T-47D cells, respectively (Fig. 2b).

The shMAP3K1 resulted in the cell cycle arrest at the G2/M phase, which indicated that the downregulation of MAP3K1 might increase drug sensitivity. As shown in Fig. 2c, we found that inhibition of MAP3K1 promoted decrease in the cell viability in tamoxifen-treated MCF7 (at 0.01, 0.1, 1, 10, and 50 $\mu \mathrm{M}$ ) and T-47D (at 0.01, 0.1, 1, 10, and $100 \mu \mathrm{M}$ ) cells when compared with cells transfected with scrambled shRNA. Furthermore, inhibition of MAP3K1 increased the cellular drug sensitivity for 
doxorubicin (at 0.01, 0.1, 1, and $2 \mu \mathrm{M}$ ) in MCF7 cells, for doxorubicin (at 0.01, 0.1, 1, 10, and $50 \mu \mathrm{M}$ ) in T47-D cells, and for docetaxel (at 0.01, 0.1, 1, 10, and $20 \mu \mathrm{M}$ ) in both MCF7 and T-47D cells (Fig. 2d and Fig. 2e).

\section{Downregulation of MAP3K1 significantly reduces the expression of cyclin B1 and anti-apoptosis-related factors, and NF-kBactivity}

We found that the expression of cyclin B1 was essentially reduced by shMAP3K1 transfection, while the expression of cyclin D1 (key molecule for $G 1$ arrest during the cell cycle) was not affected (Fig. 3a). Considering that ERK1/2 is a downstream molecule of MAP3K1-signaling pathway [20], we assessed whether ERK1/ERK2 can be inhibited by MAP3K1 silencing. We found that shMAP3K1 transfection downregulated $p$-ERK expression by $83 \%$ in MCF7 cells and by $42 \%$ in T-47D cells when compared with the scrambled group (Fig. 3a).

Previous studies have revealed that the deletion of MAP3K1 results in apoptosis when mouse embryonic stem cells are subjected to hyperosmolarity and microtubule disruption or cardiomyocytes are subjected to oxidative stress $[35,36]$. Zang et al. reported that MAP3K1 silencing inhibits cell proliferation and increases apoptosis of esophageal squamous cell carcinoma cells [37]. However, the role of MAP3K1 in regulating anti-apoptotic function in breast cancer cells remains unclear. The members of Bcl-2-related anti-apoptotic protein family, including Bcl-2 and Bcl-xL, play critical roles in the pathogenesis of ERpositive breast cancer cells [38-40]. Therefore, we assessed whether shMAP3K1 transfection led to the downregulation of expression of anti-apoptotic proteins, Bcl-2 and Bcl-xL, in both MCF7 and T-47D cells. We found that shMAP3K1 transfection downregulated Bcl-2 expression in MCF7 cells, and Bcl-xL expression in both MCF7 and T-47D cells, whereas c-Myc expression remained unaltered (Fig. 3b). Transfection with shMAP3K1 also led to increased expression of cleaved poly (ADP-ribose) polymerase (PARP) and decreased matrix metalloproteinase (MMP)-9 expression (Fig. $\mathbf{3 b}$ ). These results indicate that using shMAP3K1 to inhibit MAP3K1 can promote apoptosis and attenuate migration and invasion in these breast cancer cells.

NF-KB, acting as a downstream factor in the MAP3K1 signaling pathway, is involved in the pathogenesis of HR-positive breast cancer cells [41]. As shown in Fig. 3c, transfection with shMAP3K1 inhibited the expression of $\mathrm{p}-\mathrm{I} \mathrm{KBa}$, an essential regulatory molecule of NF-KB, in both breast cancer cell lines. Also, transfection with shMAP3K1 downregulated the nuclear expression of NF-KB (p65) in both breast cancer cell lines. Furthermore, NF-KB-dependent expression of genes, such as nuclear p52 and BCL3, was downregulated in MCF7 and T-47D cells after transfection with shMAP3K1 (Fig. 3c). As indicated by the results from the NF-KB-Luc promoter activity assay, the transcription of NF-KB-dependent genes, induced by the nuclear translocation and DNA-binding activity of NF-KB, was decreased in both breast cancer cell lines after transfection with shMAP3K1 (Fig. 3d).

Taken together, our findings indicated that MAP3K1 might play a role in promoting cell proliferation, antiapoptotic function, migration, invasion, and NF-KB transcriptional activity, and thus, contributes to 
malignant progression and poor prognosis of HR-positive, HER2-negative breast cancer patients.

\section{Expression of MAP3K1 and p-ERK in tumor cells of patients with early-stage HR-positive, HER2- negativebreast cancer}

To further validate the biological significance of involvement of MAP3K1 in proliferation, local recurrence, and metastases of HR-positive, HER2-negative breast cancer, we assessed the relationship between expression of MAP3K1 in tumor cells, and the DFS and OS of 161 patients with either T1 or T2 status and negative or 1 to 3 nodal metastases of HR-positive, HER2-negative breast cancer. As shown in Table 1, the median age was 49 years (range 23-81 years). The clinicopathological characteristics and treatments are listed in Table 1. All ER-positive and/or PR-positive patients received hormonal therapy; sixteen patients $(9.9 \%)$ received ovarian ablation or a luteinizing hormone-releasing hormone agonist with or without tamoxifen, and 145 (90.1\%) patients received tamoxifen. None of the patients received an aromatase inhibitor (which was not reimbursed by national health insurance at that time). One hundred and twenty-two patients (75.8\%) were LN-negative, whereas 39 patients $(24.2 \%)$ had 1 to $3 \mathrm{LN}$ metastases. Seventy-four patients (46.0\%) did not receive any chemotherapy, and 87 patients $(54.0 \%)$ received standard adjuvant chemotherapy (Table 1$)$. Furthermore, 121 patients (75.2\%) were positive for both ER and PR.

We detected MAP3K1 expression (51 cases, score 2; 13 cases, score 3 ) in tumor cells of 64 patients (39.8\%), whereas 97 patients exhibited negative MAP3K1 expression (92 cases, score 0; five cases, score 1) (Fig. 4a-c). Table 1 displays the demographic characteristics of the two groups of patients (MAP3K1positive vs. MAP3K1-negative) and their clinicopathological features. Age, tumor size, histological grade, axillary LN, ER and PR status, and adjuvant chemotherapy were not significantly different between the two groups.

Considering that ERK1/2 is a downstream molecule of MAP3K1-signaling pathway [20], we assessed whether the expression of p-ERK correlates with the expression of MAP3K1 in the same group of patients. In the selected 145 patients who had available tumor samples, we detected MAP3K1 expression (52 cases, score 2; 9 cases, score 3 ) in tumor cells of 61 patients (42.0\%), whereas 84 patients exhibited negative MAP3K1 expression (73 cases, score 0; 11 cases, score 1) (Fig. 4d-f). The p-ERK expression was more frequently detected in MAP3K1-positive tumors (42/59 [71.2\%]) than in MAP3K1-negative tumors $(19 / 86[22.1 \%])$ of patients $(p<0.001$, Fig. 4e and Table 1$)$.

\section{Expression of MAP3K1 or p-ERK is associated with poor clinical outcomes of patients with early-stage HR-positive, HER2-negative breast cancer}

The median follow-up period for the patients was 8.97 years ( $95 \%$ confidence interval [Cl]: 8.57 to 9.37 ); by the end of the follow-up period, 25 patients (15.5\%) exhibited local recurrence and/or distant metastases, 12 patients (7.5\%) had died (11 [91.7\%] due to breast cancer and one [8.3\%] due to causes not related to breast cancer), and 149 remained alive and healthy. The 9-year DFS and OS for all patients was $82.2 \%$ (95\% Cl: $75.3 \%$ to $89.1 \%$ ) and $91.0 \%$ (95\% Cl: $85.9 \%$ to $96.1 \%)$, respectively. 
The tumor stage $(p=0.838)$, tumor grade $(p=0.553)$, and axillary LN status $(p=0.763)$ were not associated with the 9-year DFS (Table 2). Similarly, the tumor stage $(p=0.551)$, tumor grade $(p=0.679)$, and axillary LN status ( $p=0.943$ ) were not associated with the 9-year OS (Table 2). Furthermore, we found that patients with tumor cells expressing MAP3K1 exhibited a poor 9-year DFS than those without MAP3K1 expression (72.6\% [95\% Cl: $59.5 \%$ to $85.7 \%$ ] vs. $88.5 \%$ [95\% Cl: $81.6 \%$ to $95.4 \%$ ], $p=0.022$ ) (Fig. 5a). Similarly, overexpression of MAP3K1 was significantly associated with poor 9-year OS (MAP3K1positive group vs. MAP3K1-negative group, $83.8 \%$ [95\% Cl: $73.6 \%$ to $94.0 \%$ ] vs. $96.2 \%$ [95\% Cl: $91.9 \%$ to $100 \%$ ], $p=0.012$ ) (Fig. $5 \mathbf{b}$ ). Furthermore, $\mathrm{p}$-ERK expression significantly correlated with a poor 9-year DFS (p-ERK-positive group vs. p-ERK-negative group; 74.6\% [95\% Cl: $62.3 \%$ to $86.9 \%$ ] vs. $87.3 \%$ [95\% Cl: $79.9 \%$ to $94.7 \%$ ], $p=0.033$ ) and a poor 9 -year OS ( $86.4 \%$ [95\% Cl: $78.2 \%$ to $94.6 \%]$ vs. $95.9 \%$ [95\% Cl: $91.2 \%$ to $100 \%], p=0.023$ ) (Fig. 5c-d).

Using multivariate analyses (Table 2), we found that MAP3K1 expression was still an independent prognostic factor for DFS (hazard ratio $=2.476,95 \% \mathrm{Cl}=1.112$ to $5.517, p=0.026$ ), whereas tumor stage $(p=0.769)$, histological grade $(p=0.554)$, and axillary $\operatorname{LN}(p=0.582)$ were not associated with DFS. Similarly, MAP3K1 expression was still an independent prognostic factor for OS (hazard ratio $=4.489$, $95 \% \mathrm{Cl}=1.214$ to $16.604, p=0.024)$, whereas tumor stage $(p=0.629)$, histological grade $(p=0.755)$, and axillary LN status $(p=0.983)$ did not affect OS (Table 2 ).

\section{Discussion}

In the present study, we demonstrated that MAP3K1 plays an important role in the pathogenesis of HRpositive, HER2-negative breast cancer cells. This conclusion was based on the following findings from our study: 1) the inhibition of MAP3K1 by shMAP3K1 efficiently inhibited the cell number of breast cancer cells by blocking cell cycle progression in the G2/M phase, inhibiting the G2/M phase-related cell cycle protein, cyclin B1, and by downregulating anti-apoptosis-related molecules, Bcl-2 and Bcl-xL, in MCF7 and T-47D cells, respectively; 2 ) inhibition of MAP3K1 attenuated the migration and the invasion of breast cancer cells by downregulating MMP-9 and p-ERK; 3 ) inhibition of MAP3K1 resulted in downregulation of expression of $\mathrm{p}-\mathrm{I} \mathrm{KBa}$, downregulation of NF-KB-associated genes (including $\mathrm{p} 65$ and p52), and decrease in the luciferase activity of NF-KB; 4) inhibition of MAP3K1 sensitized breast cancer cells to chemotherapy and anti-estrogen agents; 5) overexpression of MAP3K1 in tumor cells was significantly associated with the poor DFS and OS of patients with early-stage HR-positive, HER2-negative breast cancer; 6) Expression of p-ERK in tumor cells significantly correlated with the expression of MAP3K1 and poor DFS and OS of the same group of patients.

Growing evidence suggests that MAP3K1 participates in cell proliferation, invasion, and migration of human pancreatic cancer cell lines and the cell migration of ovarian cancer cell lines [42-44]. Cuevas et al. reported that in the polyoma middle $T$ antigen-driving mammary gland tumor, knockdown of MAP3K1 delays the dissemination and metastases of tumor cells [45]. Rangaswami et al. also found that the activation of MAP3K1-dependent MMP-9 signaling contributes to the osteopontin-triggered tumor growth and pulmonary metastases of melanoma [46]. These results are supported by our current findings that 
shMAP3K1 downregulated MMP-9 expression and attenuated the cellular survival, migration, and invasion in both breast cancer cell lines.

Our findings showing that shMAP3K1 caused the G2/M phase arrest in cells via downregulation of cyclin B1 further supported the results of Hu et al. that transfection with MAP3K1 small interfering RNA significantly enhances the paclitaxel-mediated cell proliferation inhibition via G2/M phase arrest and downregulation of cyclin B1 expression [34]. The G2/M phase arrest might be a potential underlying mechanism of the enhanced cytotoxicity of docetaxel [47] and doxorubicin [48] in MCF7 and T-47D cells transfected with shMAP3K1. In addition to the cell cycle arrest, we demonstrated that shMAP3K1 transfection led to induction of apoptosis via downregulation of Bcl-2 in MCF7 cells, and Bcl-xL in both MCF7 and T-47D cells, suggesting that MAP3K1 participates in the regulation of apoptosis.

Cuevas et al. reported that overexpression of MAP3K1 can promote the migration of fibroblast cells via activation of MAP3K1-ERK1/2 signaling-regulated calpain-dependent proteolysis of adhesion molecules [49]. Besides, several studies show that G protein-coupled estrogen receptor 1 (GPER, also known as GPR30) mediates the survival pathways for ER-positive breast cancer cells by triggering EGFR-dependent ERK1/2 signaling $[50,51]$. Zhao et al. found that in in vitro conditions, miRNA-302 can sensitize MCF7 and MCF7/ADR breast cancer cell lines to doxorubicin treatment via downregulation of MAP3K1/ERK signaling pathway [52]. Liu et al. revealed that p-ERK expression correlates with a poor DFS $(p=0.049)$ of 256 patients with earlystage breast cancer who received anthracyclinebased adjuvant chemotherapy [53]. In this study, we found that shMAP3K1 downregulated p-ERK and sensitized MCF7 and T-47D cells to doxorubicin. In tumor samples, our results further showed that p-ERK expression significantly correlated with MAP3K1 expression and with the poor DFS and OS of patients. These findings suggest that MAP3K1/ERK-signaling might be involved in the pathogenesis of HR-positive, HER2-negative breast cancer.

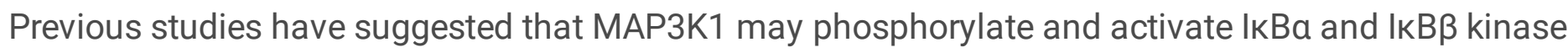
complexes and thus activate NF-KB in response to extracellular cytokines and stress [54,55]. Other studies have revealed that NF-KB is involved in the epithelial-mesenchymal transition and metastasis of breast cancer cells $[56,57]$. Following the assessment of the role of NF-KB expression in breast tumor samples, one study showed that the frequency of p65 expression is higher in tumor cells of HER2 and basal-like subtypes compared to its expression in luminal A subtype cancer cells [58]. Another study, however, reported an association between ER and NF-KB expression, where the NF-KB expression correlates with higher tumor grade, stage III-IV, and lymph node metastasis [59]. Furthermore, Oida et al. reported that NF-KB participated in the tamoxifen resistance in breast cancer cell line [60]. Previous studies have suggested that BCL3 not only activates NF-KB signaling via interaction with nuclear NF-KB p50 but also regulates the transcription of NF-KB-dependent genes [61-63]. Our findings demonstrated that inhibition of MAP3K1 downregulated NF-KB signaling pathway and BCL3 expression, and thus, suppressed cell growth of both HR-positive, HER2-negative breast cancer cell lines. Besides, inactivated NF-KB signaling may increase the sensitivity to tamoxifen in MCF7 and T-47D cells via downregulation of MAP3K1. These findings indicated that MAP3K1/NF-KB signaling might promote cell proliferation, 
enhance drug resistance, and contribute to the poor prognosis of this subtype of HR-positive, HER2negative breast cancer.

In addition to the expression of MAP3K1 in MCF7 cells, Liu et al. reported the mRNA and protein expression of MEKK1 (MAP3K1) in two triple-negative breast cancer cell lines, in human MDA-MB-231 breast cancer cells, and another murine 4T1 breast cancer cells [64]. Furthermore, Liu et al. showed that downregulation of MAP3K1 by MAP3K1targeting therapeutic artificial microRNA (amiRNA), attenuated the proliferation and inhibited the migration and invasion of murine $4 T 1$ breast cancer cells [64]. In the xenograft model of BALB/C-nude mice, MAP3K1 amiRNA suppresses tumor growth and decreases lung metastasis of murine 4T1 breast cancer cells [64]. These findings indicate that MAP3K1 may play a role in the development and progression of triple-negative breast cancer cells. Further study to explore the biological function of MAP3K1 expression in human triple-negative breast cancer cell lines and patients with triple-negative breast cancer are warranted.

\section{Conclusion}

In summary, we demonstrated that MAP3K1 acts via activation of MMP-9, ERK, and NF-KB in in vitro HRpositive, HER2-negative breast cancer cell lines, and that overexpression of MAP3K1 is significantly associated with poor DFS and OS of HR-positive, HER2-negative early-stage breast cancer patients. We also revealed that MAP3K1 signaling contributes to the resistance to chemotherapeutic drugs and antiestrogen agents. These findings suggested that MAP3K1 might act as an essential factor for promoting HR-positive, HER2-negative breast cancer cell proliferation, migration, invasion, and resistance to the drugs, and thus, for increasing local recurrences and metastases of this subtype of breast cancer (Fig. 5e). Further studies on the possible relationship between MAP3K1 signaling and anti-apoptosis related proteins, such as $\mathrm{Bcl}-2$ and $\mathrm{Bcl}-\mathrm{xL}$, are needed. Nevertheless, our results further elucidated the expression profiles of MAP3K1 in both experimental cancer cell lines and clinical specimens, and thus, it may facilitate the development of novel MAP3K1-related therapeutic strategies for this subtype of HRpositive, HER2-negative breast cancer.

\section{Abbreviations}

MAP3K1: Mitogen-Activated Protein Kinase Kinase Kinase 1; HR, hormone receptor; HER2: human epidermal growth factor receptor 2; IHC: immunohistochemistry; ER: estrogen receptor; PR: progesterone receptor (PR): FISH: fluorescence in situ hybridization; GWAS; genome-wide association studies; SNP: single nucleotide polymorphisms; DFS: disease-free survival; OS: overall survival; ERK: extracellularsignal-regulated kinase; LN: lymph node; p: phospho; SD, standard deviation.

\section{Declarations}

Acknowledgments: 
The authors would like to thank the Cancer Registry, Cancer Administration and Coordination Center, National Taiwan University Hospital, for providing the necessary patient information, and thank the Taiwan Breast Cancer Consortium (TBCC) for their help.

\section{Author Contributions:}

SHK designed the study and participated in the data acquisition, analysis, and interpretation, and writing and reviewing of the manuscript. MFW, WCY, JCL. performed the laboratory work. YHL participated in the pathologic review and immunohistochemical data interpretation. SYY performed the statistical analysis. $\mathrm{CSH}$ participated in the data acquisition, analysis, and interpretation, writing, and reviewing of the manuscript, administrative, technical, and material support. All authors contributed to the interpretation of the results and critically reviewed the draft of the manuscript, read and approved the final version of the manuscript.

\section{Funding}

This research was funded by MOST 107-2314-B-002-132-MY3 and 109-2321-B-002-038 from the Ministry of Science and Technology, Taiwan, and MOHW109-TDU-B-211-134017 from the Ministry of Health and Welfare, Taiwan.

\section{Availability of data and materials}

All data presented and analyzed during this study are included in this article.

\section{Ethics approval and consent to participate}

The immunohistochemical analyses of MAP3K1 protein expression and detailed demographic information were obtained from the patients and their medical charts with their written informed consent (strict compliance to the Declaration of Helsinki.). The pathologic review and immunohistochemical studies were approved by the National Taiwan University Hospital (NTUH) ethics committee (Institutional Review Board [IRB] Number: 201804056RINB). The patients' medical data were anonymized before access and analysis.

\section{Consent for publication}

Not applicable.

\section{Competing interests}

The authors declare that they have no conflict of interests.

\section{References}


1. Ghoncheh M, Pournamdar Z, Salehiniya H. Incidence and Mortality and Epidemiology of Breast Cancer in the World. Asian Pac J Cancer Prev. 2016;17(S3):43-4

2. Lin $\mathrm{CH}$, Chen YC, Chiang CJ, Lu YS, Kuo KT, Huang CS, et al. The emerging epidemic of estrogenrelated cancers in young women in a developing Asian country. Int J Cancer. 2012;130:2629-26

3. Perou CM, Sørlie T, Eisen MB, van de Rijn M, Jeffrey SS, Rees CA, et al. Molecular portraits of human breast tumours. Nature. 2000;406:747-7

4. Sørlie T, Perou CM, Tibshirani R, Aas T, Geisler S, Johnsen H, et al. Gene expression patterns of breast carcinomas distinguish tumor subclasses with clinical implications. Proc Natl Acad Sci USA. 2001;98:10869-108

5. Goldhirsch A, Winer EP, Coates AS, Gelber RD, Piccart-Gebhart M, Thürlimann B, Senn HJ; Panel members. Personalizing the treatment of women with early breast cancer: highlights of the St Gallen International Expert Consensus on the Primary Therapy of Early Breast Cancer 2013. Ann Oncol. 2013;24:2206-2223.

6. Curigliano G, Burstein HJ, Winer EP, Gnant M, Dubsky P, Loibl S, et al. De-escalating and escalating treatments for early-stage breast cancer: the St. Gallen International Expert Consensus Conference on the Primary Therapy of Early Breast Cancer 2017. Ann Oncol. 2017;28:1700-1712.

7. Early Breast Cancer Trialists' Collaborative Group (EBCTCG). Effects of chemotherapy and hormonal therapy for early breast cancer on recurrence and 15-year survival: an overview of the randomised trials. Lancet. 2005; 365:1687-717.

8. Kuo SH, Lien HC, You SL, Lu YS, Lin CH, Chen TZ, et al. Dose variation and regimen modification of adjuvant chemotherapy in daily practice affect survival of stage I-II and operable stage III Taiwanese breast cancer patients. Breast. 2008;17:646-6

9. Early Breast Cancer Trialists' Collaborative Group (EBCTCG), Peto R, Davies C, Godwin J, Gray R, Pan $\mathrm{HC}$, Clarke $\mathrm{M}$, et al. Comparisons between different polychemotherapy regimens for early breast cancer: meta-analyses of long-term outcome among 100,000 women in 123 randomised trials. Lancet. 2012;379:432-444.

10. Sparano JA, Gray RJ, Makower DF, Pritchard KI, Albain KS, Hayes DF, et al. Prospective validation of a 21-gene expression assay in breast cancer. N Engl J Med. 2015;373:2005-2014.

11. Cardoso F, van't Veer LJ, Bogaerts J, Slaets L, Viale G, Delaloge S, et al; MINDACT Investigators. 70Gene signature as an aid to treatment decisions in early-stage breast cancer. N Engl J Med. 2016;375:717-729.

12. Gnant M, Filipits M, Greil R, Stoeger H, Rudas M, Bago-Horvath Z, et al; Austrian Breast and Colorectal Cancer Study Group. Predicting distant recurrence in receptor-positive breast cancer patients with limited clinicopathological risk: using the PAM50 Risk of Recurrence score in 1478 postmenopausal patients of the ABCSG-8 trial treated with adjuvant endocrine therapy alone. Ann Oncol. 2014;25: 339-345.

13. Sestak I, Buus R, Cuzick J, Dubsky P, Kronenwett R, Denkert C, et al. Comparison of the Performance of 6 Prognostic Signatures for Estrogen Receptor-Positive Breast Cancer: A Secondary Analysis of a 
Randomized Clinical Trial. JAMA Oncol. 2018;4: 545-553.

14. Easton DF, Pooley KA, Dunning AM, Pharoah PD, Thompson D, Ballinger DG, et al. Genome-wide association study identifies novel breast cancer susceptibility loci. 2007;447:1087-1093.

15. Klinge CM, Blankenship KA, Risinger KE, Bhatnagar S, Noisin EL, Sumanasekera WK, et al.

Resveratrol and estradiol rapidly activate MAPK signaling through estrogen receptors alpha and beta in endothelial cells. J Biol Chem. 2005;280:7460-746

16. Lu PH, Yang J, Li C, Wei MX, Shen W, Shi LP, et al. Association between mitogen-activated protein kinase kinase kinase 1 rs889312 polymorphism and breast cancer risk: evidence from 59,977 subjects. Breast Cancer Res Treat. 2011;126:663-6

17. Kuo SH, Yang SY, You SL, Lien HC, Lin CH, Lin PH, et al. Polymorphisms of ESR1, UGT1A1, HCN1, MAP3K1 and CYP2B6 are associated with the prognosis of hormone receptor-positive early breast cancer. 2017;8:20925-20938.

18. Uhlik MT, Abell AN, Cuevas BD, Nakamura K, Johnson GL. Wiring diagrams of MAPK regulation by MEKK1, 2, and 3. Biochem Cell Biol. 2004; 82:658-6

19. Kato S, Endoh H, Masuhiro Y, Kitamoto T, Uchiyama S, Sasaki H, et al. Activation of the estrogen receptor through phosphorylation by mitogenactivated protein kinase. Science. 1995;270:1491-149

20. Pham TT, Angus SP, Johnson GL. MAP3K1: Genomic Alterations in Cancer and Function in Promoting Cell Survival or Apoptosis. Genes Cancer. 2013;4:419-4

21. Small GW, Shi YY, Higgins LS, Orlowski RZ. Mitogen-activated protein kinase phosphatase-1 is a mediator of breast cancer chemoresistance. Cancer Res. 2007;67:4459-4466.

22. Haagenson KK, Wu GS. The role of MAP kinases and MAP kinase phosphatase-1 in resistance to breast cancer treatment. Cancer Metastasis Rev. 2010;29:143-14

23. Stephens, PJ, Tarpey PS, Davies H, Van Loo P, Greenman C, Wedge DC, et al. The landscape of cancer genes and mutational processes in breast cancer. 2012;486:400-404.

24. Cancer Genome Atlas Network. Comprehensive molecular portraits of human breast tumours. Nature. 2012;490:61-70.

25. Hanieh H, Mohafez O, Hairul-Islam VI, Alzahrani A, Bani Ismail M, Thirugnanasambantham K. Novel Aryl Hydrocarbon Receptor Agonist Suppresses Migration and Invasion of Breast Cancer Cells. PLoS One. 2016;11:e0167650.

26. Chen YH, Wang CW, Wei MF, Tzeng YS, Lan KH, Cheng AL, et al. Maintenance BEZ235 Treatment Prolongs the Therapeutic Effect of the Combination of BEZ235 and Radiotherapy for Colorectal Cancer. Cancers (Basel). 2019;11:pii: E1204.

27. Kuo SH, Chou CH, Cheng AL, Wang CW, Chen YH, Chen RJ. Expression of BCL10 in cervical cancer has a role in the regulation of cell growth through the activation of NF-kB-dependent cyclin D1 signaling. Gynecol Oncol. 2012;126:245-2

28. Guan KL. The mitogen activated protein kinase signal transduction pathway: from the cell surface to the nucleus. Cell Signal.1994;6:581-58 
29. Kuo SH, Tsai HJ, Lin CW, Yeh KH, Lee HW, Wei MF, et al. The B-cell-activating factor signalling pathway is associated with Helicobacter pylori independence in gastric mucosa-associated lymphoid tissue lymphoma without $t(11 ; 18)(q 21 ; q 21)$. J Pathol. 2017;241:420-4

30. Kuo SH, Yeh KH, Chen LT, Lin CW, Hsu PN, Wu MS, et al. Helicobacter pylori CagA Translocation Is Closely Associated With the Expression of CagA-signaling Molecules in Low-grade Gastric Mucosaassociated Lymphoid Tissue Lymphoma. Am J Surg Pathol. 2015;39:761-766.

31. Sauter G, Lee J, Bartlett JM, Slamon DJ, Press MF. Guidelines for human epidermal growth factor receptor 2 testing: biologic and methodologic considerations. J Clin Oncol. 2009;27:1323-1333.

32. Qiao H, Zhang X, Zhu C, Dong L, Wang L, Zhang X, et al. Luteolin downregulates TLR4, TLR5, NF-kB and p-p38MAPK expression, upregulates the $p$-ERK expression, and protects rat brains against focal ischemia. Brain Res. 2012;1448:71-81.

33. Hudis CA, Barlow WE, Costantino JP, Gray RJ, Pritchard KI, Chapman JA, et al. Proposal for standardized definitions for efficacy end points in adjuvant breast cancer trials: the STEEP system. J Clin Oncol. 2007;25: 2127-21

34. Hu P, Huang Q, Li Z, Wang H, Gu J, Gui Z, et al. Silencing MAP3K1 expression through RNA interference enhances paclitaxel-induced cell cycle arrest in human breast cancer cells. Mol Biol Rep. 2014;41:19-24.

35. Yujiri T, Sather S, Fanger GR, Johnson GL. Role of MEKK1 in cell survival and activation of JNK and ERK pathways defined by targeted gene disruption. Science. 1998;282:1911-1914.

36. Minamino T, Yujiri T, Papst PJ, Chan ED, Johnson GL, Terada N. MEKK1 suppresses oxidative stressinduced apoptosis of embryonic stem cell-derived cardiac myocytes. Proc Natl Acad Sci U S A. 1999;96:15127-15132.

37. Zang WQ, Yang X, Wang T, Wang YY, Du YW, Chen XN, et al. MiR-451 inhibits proliferation of esophageal carcinoma cell line EC9706 by targeting CDKN2D and MAP3K1. World J Gastroenterol. 2015;21:5867-5876.

38. Yip KW, Reed JC. Bcl-2 family proteins and cancer. Oncogene. 2008;27: 6398-6406.

39. Eom YH. Kim HS, Lee A, Song BJ, Chae BJ. BCL2 as a Subtype-Specific Prognostic Marker for Breast Cancer. J Breast Cancer. 2016;19:252-260.

40. Fiebig AA, Zhu W, Hollerbach C, Leber B, Andrews DW. Bcl-XL is qualitatively different from and ten times more effective than Bcl-2 when expressed in a breast cancer cell line. BMC Cancer. 2006;6:213.

41. Yde CW, Emdal KB, Guerra B, Lykkesfeldt AE. NFKB signaling is important for growth of antiestrogen resistant breast cancer cells. Breast Cancer Res Treat. 2012;135:67-

42. Hirano T, Shino Y, Saito T, et al. Dominant negative MEKK1 inhibits survival of pancreatic cancer cells. Oncogene. 2002;21:5923-5928.

43. Su F, Li H, Yan C, Jia B, Zhang Y, Chen X. Depleting MEKK1 expression inhibits the ability of invasion and migration of human pancreatic cancer cells. J Cancer Res Clin Oncol. 2009;135:1655-1663. 
44. Bian D, Su S, Mahanivong C, Cheng RK, Han Q, Pan ZK, et al. Lysophosphatidic acid stimulates ovarian cancer cell migration via a Ras-MEK Kinase 1 pathway. Cancer Res. 2004;64:4209-4217.

45. Cuevas BD, Winter-Vann AM, Johnson NL, Johnson GL. MEKK1 controls matrix degradation and tumor cell dissemination during metastasis of polyoma middle-T driven mammary cancer. Oncogene. 2006;25:4998-5010.

46. Rangaswami H, Kundu GC. Osteopontin stimulates melanoma growth and lung metastasis through NIK/MEKK1-dependent MMP-9 activation pathways. Oncol Rep. 2007;18:909-915.

47. O'Leary J, Volm M, Wasserheit C, Muggia F. Taxanes in adjuvant and neoadjuvant therapies for breast cancer. Oncology (Williston Park). 1998;12(1 Suppl 1):23-27.

48. Bar-On O, Shapira M, Hershko DD. Differential effects of doxorubicin treatment on cell cycle arrest and Skp2 expression in breast cancer cells. Anticancer Drugs. 2007;18:1113-1121.

49. Cuevas BD, Abell AN, Witowsky JA, Yujiri T, Johnson NL, Kesavan K, et al. MEKK1 regulates calpaindependent proteolysis of focal adhesion proteins for rear-end detachment of migrating fibroblasts. EMBO J. 2003;22:3346-3355.

50. Filardo EJ. Epidermal growth factor receptor (EGFR) transactivation by estrogen via the G-proteincoupled receptor, GPR30: a novel signaling pathway with potential significance for breast cancer. J Steroid Biochem Mol Bio. 2002;80:231-238.

51. Li M, Guo J, Gao W, Yu J, Han X, Zhang J, Shao B. BisphenolAF-induced endogenous transcription is mediated by ERa and ERK1/2 activation inhuman breast cancer PLoS One. 2014;9:e94725.

52. Zhao L, Wang Y, Jiang L, He M, Bai X, Yu L, et al. MiR-302a/b/c/d cooperatively sensitizes breast cancer cells to adriamycin via suppressing P-glycoprotein(P-gp) by targeting MAP/ERK kinase kinase 1 (MEKK1). J Exp Clin Cance Res.2016; 35:25.

53. Liu W, Zhang L, Shi J, Liu Y, Zhou L, Hou K, et al. Clinicalsignificance of pAkt and pErk1/2 expression in early-stage breast cancer patients treated with anthracycline-based adjuvant chemotherapy. Oncol Lett. 2015;9:1707-14.

54. Lee FS, Peters RT, Dang LC, Maniatis T. MEKK1 activates both IkappaB kinase alpha and IkappaB kinase beta. Proc Natl Acad Sci USA. 1998;95: 9319-9324.

55. Bonvin C, Guillon A, van Bemmelen MX, Gerwins P, Johnson GL, Widmann C. Role of the aminoterminal domains of MEKKs in the activation of NF kappa B and MAPK pathways and in the regulation of cell proliferation and apoptosis. Cell Signal. 2002;14:123-1

56. Huber MA, Azoitei N, Baumann B, Grünert S, Sommer A, Pehamberger H. NF-kappaB is essential for epithelial-mesenchymal transition and metastasis in a model of breast cancer progression. $\mathrm{J}$ Clin Invest. 2004; 114:569-5

57. Castellaro AM, Rodriguez-Baili MC, Di Tada CE, Gil GA. Tumor-Associated Macrophages Induce Endocrine Therapy Resistance in ER+ Breast Cancer Cells. Cancers (Basel). 2019;11:pii:E189.

58. Shapochka DO, Zaletok SP, Gnidyuk MI. Relationship between NF-KB, ER, PR, Her2/neu, Ki67, p53 expression in human breast cancer. Exp Oncol. 2012;34:358-3 
59. Zhou XL, Fan W, Yang G, Yu MX. The clinical significance of PR, ER, NF-KB, and TNF-a in breast cancer. Dis Markers. 2014;2014:494581

60. Oida $K$, Matsuda A, Jung K, Xia Y, Jang H, Amagai Y, et al. Nuclear factor-KB plays a critical role in both intrinsic and acquired resistance against endocrine therapy in human breast cancer Sci Rep. 2014;4:4057.

61. Thornburg NJ, Pathmanathan R, Raab-Traub N. Activation of nuclear factor-kappaB p50 homodimer/Bcl-3 complexes in nasopharyngeal carcinoma. Cancer Res. 2003;63:8293-8

62. Yeh PY, Kuo SH, Yeh $\mathrm{KH}$, Chuang $\mathrm{SE}, \mathrm{Hsu} \mathrm{CH}$, Chang WC, et al. A pathway for tumor necrosis factoralpha-induced $\mathrm{Bcl} 10$ nuclear translocation. Bcl10 is up-regulated by NF-kappaB and phosphorylated by Akt1 and then complexes with Bcl3to enter the nucleus. J Biol Chem. 2006; 281:167-1

63. Collins PE, Kiely PA, Carmody RJ. Inhibition of transcription by B cell Leukemia 3 (Bcl-3) protein requires interaction with nuclear factor KB (NF-KB) p50. J Biol Chem. 2014;289:7059-70

64. Liu C, Wang S, Zhu S, Wang H, Gu J, Gui Z, et al. MAP3K1-targeting therapeutic artificial miRNA suppresses the growth and invasion of breast cancer in vivo and in vitro. 2016;5:11.

\section{Tables}


Table 1

Clinicopathological features between MAP3K1-negative and MAP3K1-positive groups of HR-positive, HER2-negative breast cancer

\section{MAP3K1}

\begin{tabular}{|c|c|c|c|c|}
\hline & Total (N) & Negative & Positive & P-value \\
\hline Number & 161 & $97(60.2 \%)$ & $64(39.8 \%)$ & \\
\hline Age & & & & $0.130 \dagger$ \\
\hline Median & 49 & 47.5 & 50 & \\
\hline Range & $23-81$ & $23-81$ & $35-74$ & \\
\hline T-stage & & & & $0.691 \ddagger$ \\
\hline T1 & $71(44.1 \%)$ & $44(45.4 \%)$ & $27(42.2 \%)$ & \\
\hline $\mathrm{T} 2$ & $90(55.9 \%)$ & $53(54.6 \%)$ & $37(57.8 \%)$ & \\
\hline Grade & & & & $0.390 \S$ \\
\hline 1 & $62(38.5 \%)$ & $41(42.3 \%)$ & $21(32.8 \%)$ & \\
\hline 2 & $81(50.3 \%)$ & $45(46.4 \%)$ & $36(56.2 \%)$ & \\
\hline 3 & $18(11.2 \%)$ & $11(11.3 \%)$ & $7(11.0 \%)$ & \\
\hline Axillary LN & & & & $0.852 \ddagger$ \\
\hline Negative & $122(75.8 \%)$ & $74(76.7 \%)$ & $48(75.0 \%)$ & \\
\hline Positive & $39(24.2 \%)$ & $23(23.3 \%)$ & $16(25.0 \%)$ & \\
\hline ER and PR status & & & & $0.407 \S$ \\
\hline $\mathrm{ER}(+) \mathrm{PR}(+)$ & $121(75.2 \%)$ & $75(77.3 \%)$ & $46(71.8 \%)$ & \\
\hline $\mathrm{ER}(+) / \mathrm{PR}(-)$ & $21(13.0 \%)$ & $12(12.4 \%)$ & $9(14.1 \%)$ & \\
\hline $\mathrm{ER}(-) / \mathrm{PR}(+)$ & $19(11.8 \%)$ & $10(10.3 \%)$ & $9(14.1 \%)$ & \\
\hline Chemotherapy & & & & $0.206 \ddagger$ \\
\hline
\end{tabular}

Abbreviation: HR, hormone receptor; HER2, human epidermal growth factor receptor 2; LN, lymph node; ER, estrogen receptor; PR, progesterone receptor; $C E$, cyclophosphamide and epirubicin; CMF, cyclophosphamide, methotrexate, and fluorouracil; AC, anthracycline and cyclophosphamide; Taxanes, paclitaxel or docetaxel; p-EGFR, phospho-extracellular signal-regulated kinase.

tP values (2-sided) were calculated using the Student $t$ test.

$\ddagger P$ values (2-sided) were calculated using the $\times 2$ test or the Fisher exact test.

$\S P$ values (2-sided) were calculated using 1-way analysis of variance. 


\begin{tabular}{|c|c|c|c|c|}
\hline \multicolumn{5}{|c|}{ MAP3K1 } \\
\hline No & $74(46.0 \%)$ & $47(48.5 \%)$ & $27(42.2 \%)$ & \\
\hline CE & $45(28.0 \%)$ & $29(29.9 \%)$ & $16(25.0 \%)$ & \\
\hline CMF & $32(19.9 \%)$ & $15(15.5 \%)$ & $17(26.6 \%)$ & \\
\hline AC & $7(4.2 \%)$ & $5(5.1 \%)$ & $2(3.1 \%)$ & \\
\hline Taxanes & $3(1.9 \%)$ & $1(1.0 \%)$ & $2(3.1 \%)$ & \\
\hline \multicolumn{4}{|l|}{$\begin{array}{l}\text { p-ERK expression } \\
(\mathrm{N}=145)\end{array}$} & $<0.001$ \\
\hline Negative & $84(57.9 \%)$ & $67(77.9 \%)$ & $17(28.8 \%)$ & \\
\hline Positive & $61(42.1 \%)$ & $19(22.1 \%)$ & $42(71.2 \%)$ & \\
\hline \multicolumn{5}{|c|}{$\begin{array}{l}\text { Abbreviation: HR, hormone receptor; HER2, human epidermal growth factor receptor 2; LN, lymph } \\
\text { node; ER, estrogen receptor; PR, progesterone receptor; CE, cyclophosphamide and epirubicin; CMF, } \\
\text { cyclophosphamide, methotrexate, and fluorouracil; AC, anthracycline and cyclophosphamide; } \\
\text { Taxanes, paclitaxel or docetaxel; } \text { p-EGFR, phospho-extracellular signal-regulated kinase. }\end{array}$} \\
\hline \multicolumn{5}{|c|}{ tP values (2-sided) were calculated using the Student $t$ test. } \\
\hline \multicolumn{5}{|c|}{$\ddagger \mathrm{P}$ values (2-sided) were calculated using the $\mathrm{x} 2$ test or the Fisher exact test. } \\
\hline$\S P$ values (2-sided & culated usins & nalysis of va & & \\
\hline
\end{tabular}


Table 2

Univariate and multivariate analyses of the relationship between pathological features and expression of MAP3K1 and clinical outcomes of HR-positive and HER2-negative breast cancer patients

\begin{tabular}{|c|c|c|c|c|c|c|}
\hline \multirow[b]{2}{*}{ DFS } & \multicolumn{3}{|c|}{ Univariate analyses } & \multicolumn{3}{|c|}{ Multivariate analyses } \\
\hline & $\mathrm{HR}^{*}$ & $95 \% \mathrm{Cl}$ & $P$ value & $\mathrm{HR}^{*}$ & $95 \% \mathrm{Cl}$ & \\
\hline $\begin{array}{l}\text { T-stage } \\
\text { T2 vs. T1 }\end{array}$ & 0.921 & $0.418-2.031$ & 0.838 & 0.887 & $0.401-1.966$ & 0.769 \\
\hline $\begin{array}{l}\text { Grade } \\
\text { III vs. I+ II }\end{array}$ & 1.176 & $0.689-2.007$ & 0.553 & 1.176 & $0.688-2.009$ & 0.554 \\
\hline $\begin{array}{l}\text { LN } \\
\text { Pos vs. Neg }\end{array}$ & 0.763 & $0.286-2.033$ & 0.763 & 0.758 & $0.283-2.030$ & 0.582 \\
\hline $\begin{array}{l}\text { MAP3K1 } \\
\text { Pos vs. Neg }\end{array}$ & 2.465 & $1.107-5.488$ & 0.027 & 2.476 & $1.112-5.517$ & 0.026 \\
\hline os & $H R^{*}$ & $95 \% \mathrm{Cl}$ & $P$ value & $\mathrm{HR}^{*}$ & $95 \% \mathrm{Cl}$ & $P$ value \\
\hline $\begin{array}{l}\text { T-stage } \\
\text { T2 vs. T1 }\end{array}$ & 1.142 & $0.433-4.795$ & 0.551 & 1.348 & $0.402-4.514$ & 0.629 \\
\hline $\begin{array}{l}\text { Grade } \\
\text { III vs. I+ II }\end{array}$ & 1.174 & $0.549-2.508$ & 0.679 & 1.129 & $0.526-2.423$ & 0.755 \\
\hline $\begin{array}{l}\text { LN } \\
\text { Pos vs. Neg }\end{array}$ & 1.049 & $0.284-3.875$ & 0.943 & 0.986 & $0.263-3.699$ & 0.983 \\
\hline $\begin{array}{l}\text { MAP3K1 } \\
\text { Pos vs. Neg }\end{array}$ & 4.559 & $1.234 * 16.848$ & 0.023 & 4.489 & $1.214-16.604$ & 0.024 \\
\hline $\begin{array}{l}\text { Abbreviation } \\
\text { HER-2, huma } \\
\text { confidence ir }\end{array}$ & $\begin{array}{l}\text { AP3K1 } \\
\text { derma } \\
\mathrm{l} ; \mathrm{T}, \mathrm{tc}\end{array}$ & $\begin{array}{l}\text { togen-activate } \\
\text { owth factor re } \\
\text { r; LN, lymph n }\end{array}$ & $\begin{array}{l}\text { tein kin } \\
\text { r 2; DFs } \\
\text { Dos, pos }\end{array}$ & $\begin{array}{l}\text { inas } \\
\text { ease } \\
\text { Neg }\end{array}$ & $\begin{array}{l}\text { inase } 1 ; \mathrm{HR} \text {, hormo } \\
\text { e survival; } \mathrm{HR}^{\star} \text {, ha } \\
\text { gative; OS, overall }\end{array}$ & $\begin{array}{l}\text { eptor; } \\
\text { tio; Cl, } \\
\text { al. }\end{array}$ \\
\hline
\end{tabular}

\section{Figures}


b

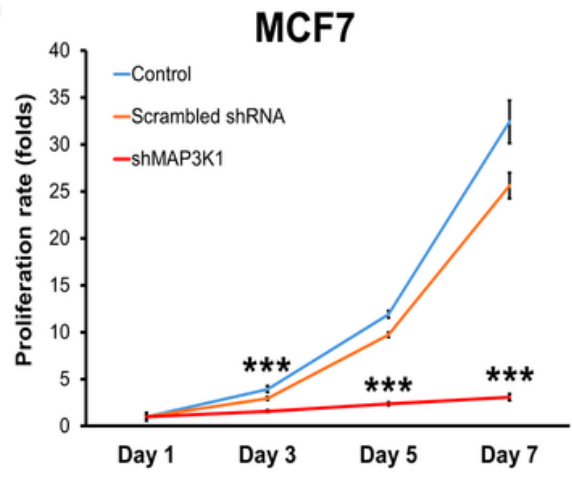

T-47D

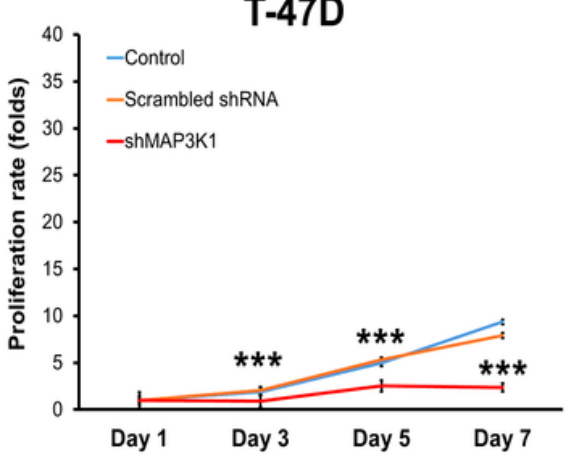

C

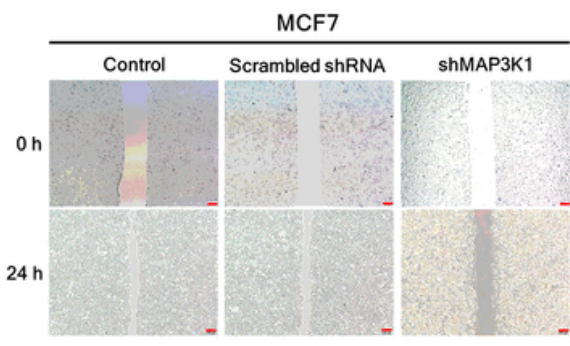

T-47D

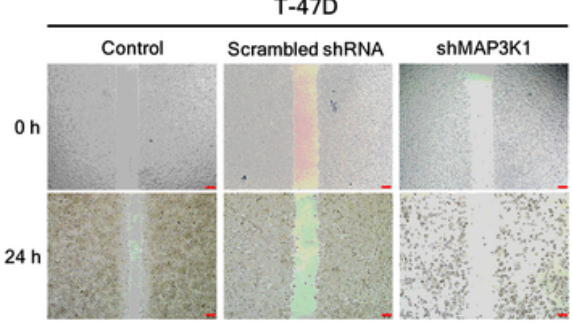

Actin

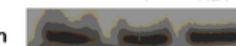

d
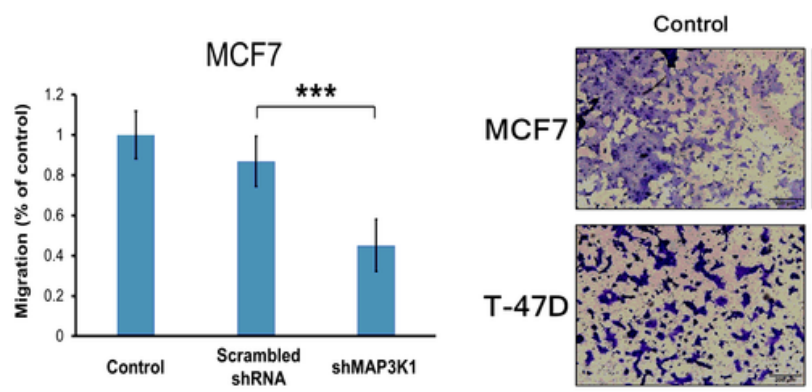

MCF7
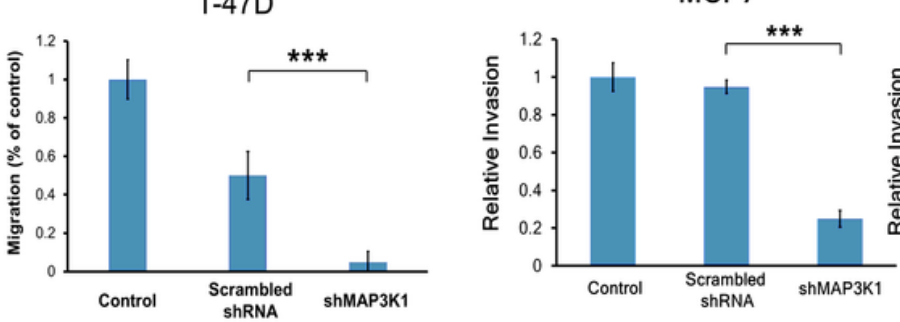

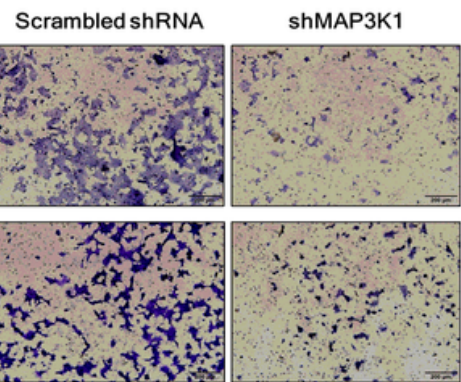

T-47D

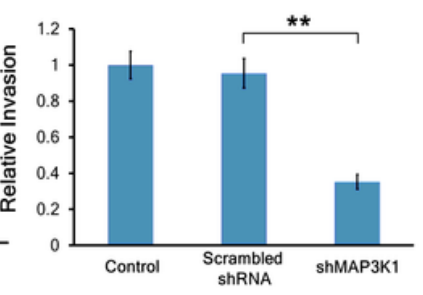

Figure 1

\section{Figure 1}

Silencing of the MAP3K1 gene inhibits cellular proliferation and migration in HR-positive, HER2-negative breast cancer cell lines. a Two breast cancer cell lines, MCF7 and T-47D, were infected with PGIPZ lentiviral (scrambled) and MAP3K1 shRNA lentiviral vectors. The protein expression of MAP3K1 was examined by western blotting analysis. The data showed an efficient knockdown of MAP3K1 in breast cancer cell lines transfected with shMAP3K1, and therefore, we used this shRNA to conduct further experiments. b Proliferation assay showed that the MAP3K1-silenced cell line exhibited a significant reduction in cell number compared to the scrambled group of the same cell line. c Cell migration assay showed that MAP3K1 knockdown inhibited breast cancer cell migration at 24 hours (no differences between scrambled- and shMAP3K1-transfected breast cancer cell lines). Data are shown as mean \pm SD from three independent experiments. $d$ Invasion assay showed that MAP3K1 knockdown suppressed breast cancer cell invasion in both shMAP3K1-transfected MCF7 and T-47D cells when compared with scrambled MCF7 and T-47D cells. The invaded cells were stained with crystal violet and counted in four different microscopic fields. Data are shown as mean \pm SD from three independent experiments. ${ }^{\star \star}, \mathrm{p}<$ 
$0.01 ; * \star \star, p<0.001$. MAP3K1, mitogen-activated protein kinase kinase kinase 1; HR, hormone receptor; HER-2, human epidermal growth factor receptor 2; shRNA, short hairpin RNA; SD, standard deviation.

a

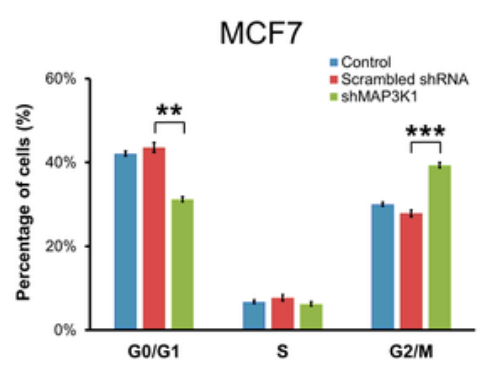

b

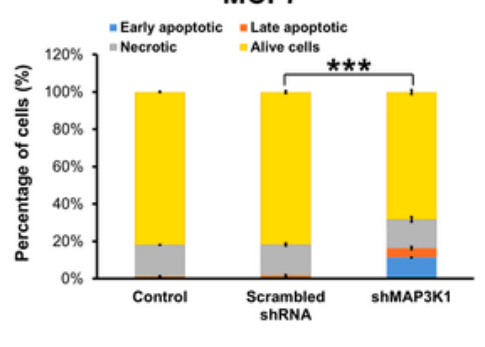

C

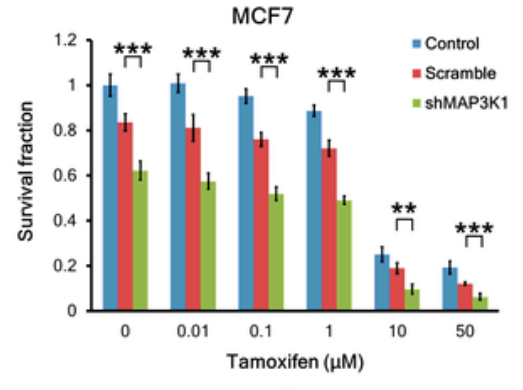

d

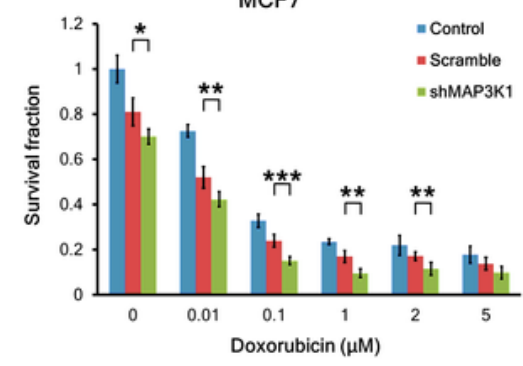

e

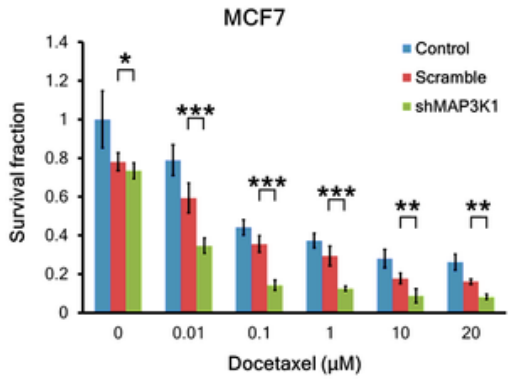

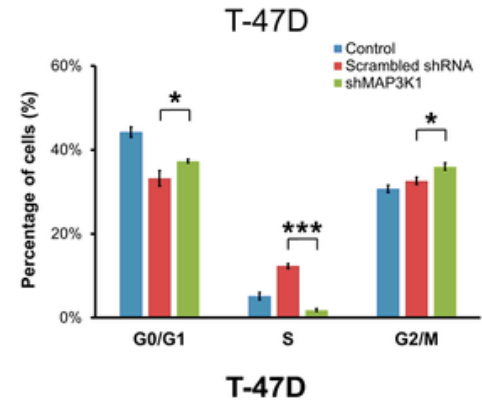
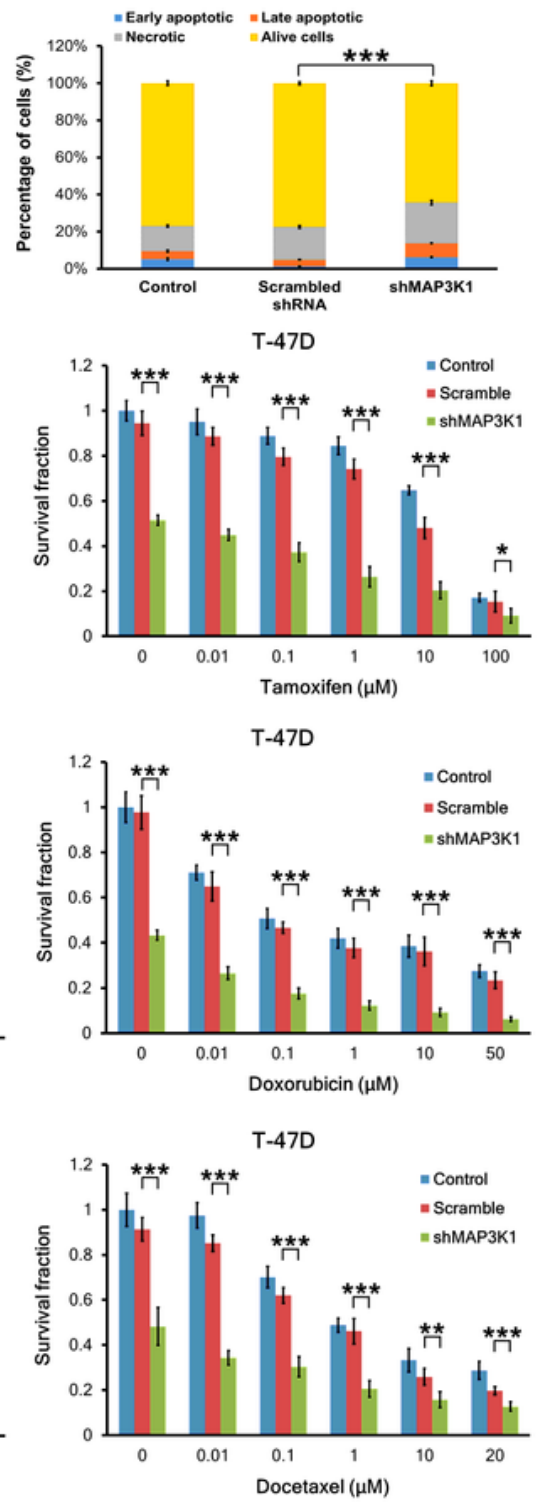

Figure 2

Figure 2

Inhibition of MAP3K1 causes G2/M phase arrest and increases drug sensitivity in HR-positive, HER2negative breast cancer cell lines. a shMAP3K1 transfection resulted in G2/M phase arrest in both MCF-7 and T-47D cells. The results are expressed as the mean \pm SD of three independent experiments from each 
cell line. b Summary of the Annexin V-FITC apoptosis assay results showing the percentages of early apoptotic, late apoptotic, necrotic, and living cells. The results are expressed as the mean \pm SD of three independent experiments from each cell line. Annexin V staining revealed that shMAP3K1 treatment resulted in more prominent apoptosis in both MCF7 and T-47D cells. c shMAP3K1 promoted inhibition of cell viability in tamoxifen-treated MCF7 and T-47D cells when compared with scrambled groups. $\mathrm{d}$ shMAP3K1 promoted inhibition of cell viability in doxorubicin-treated MCF7 and T-47D cells when compared to the scrambled groups. e shMAP3K1 increased the sensitivity to docetaxel in both MCF7 and T-47D breast cancer cells. *, $p<0.05 ; * \star, p<0.01 ; * \star *, p<0.001$. MAP3K1, mitogen-activated protein kinase kinase kinase 1; HR, hormone receptor; HER-2, human epidermal growth factor receptor 2; shRNA, short hairpin RNA; SD, standard deviation.

a

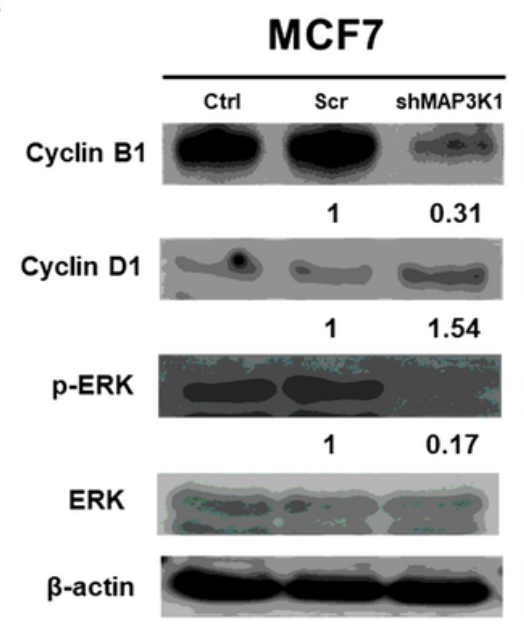

C

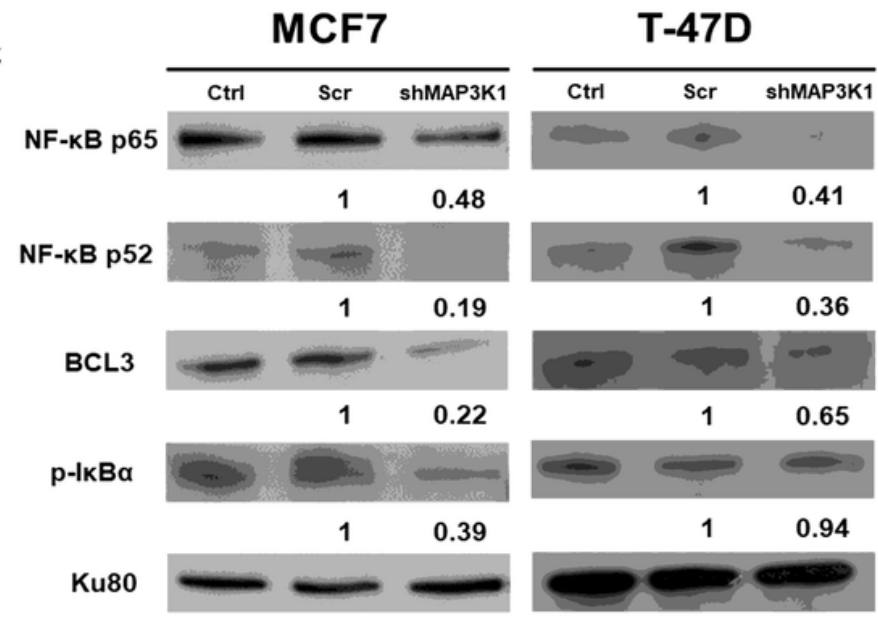

b
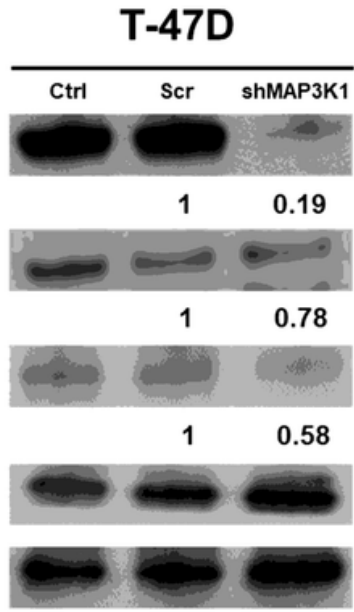

MMP-9

a-tubulin

d

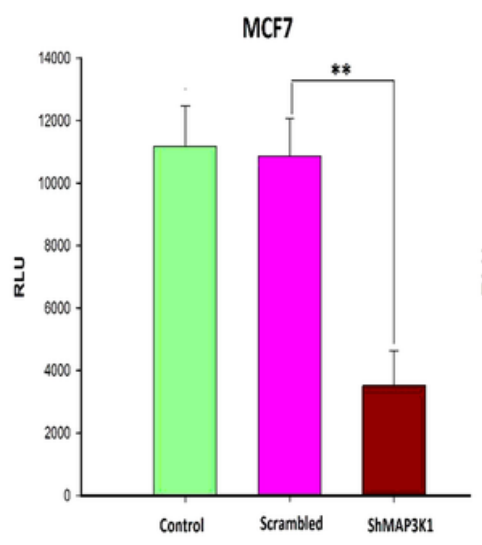

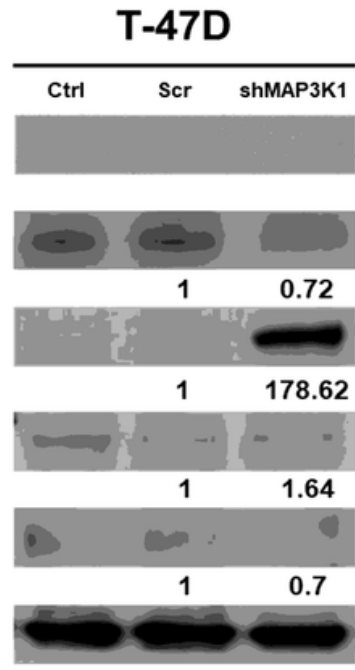

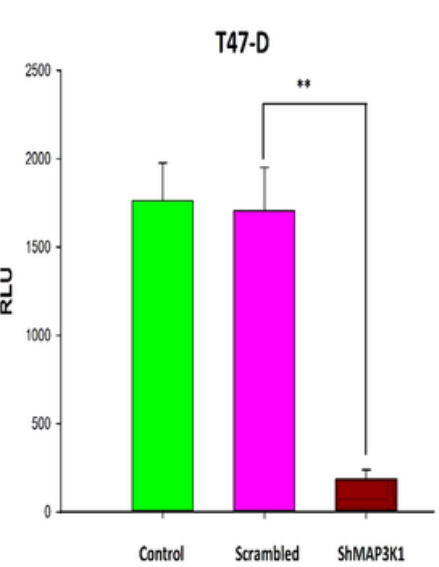

Figure 3

\section{Figure 3}

Inhibition of MAP3K1 downregulates cell cycle-, anti-apoptosis-, and MAP3K1-related proteins and decreases the NF-KB-dependent gene transcription. a shMAP3K1 transfection downregulated the expression of cyclin B1 and p-ERK; however, it did not affect cyclin D1 in total cell lysates of both MCF-7 and T-47D cancer cells. b shMAP3K1 transfection downregulated the expression of $\mathrm{Bcl}-2, \mathrm{Bcl}-\mathrm{xL}$, and 
MMP-9, and increased the levels of c-PARP; however, it did not affect c-Myc expression in total cell lysates of MCF7 cells. shMAP3K1 transfection decreased the expression of Bcl-xL and MMP-9, and increased the c-PARP levels; however, it did not affect c-Myc expression in total cell lysates of T-47D cells. c shMAP3K1 decreased the expression of p65, p52, and BCL3 in nuclear lysates, and p-IKBa in total lysates of both MCF7 and T-47D breast cancer cells. $d$ The results from three independent experiments using shMAP3K1transfected MCF7 and T-47D cells are presented as RLU per milligram of protein (NF-KB-Luc promoter activity-luciferase assay) (**, $p<0.01)$. MAP3K1, mitogen-activated protein kinase kinase kinase $1 ; H R$, hormone receptor; HER-2, human epidermal growth factor receptor 2; shRNA, short hairpin RNA; p-ERK, phospho-extracellular signal-regulated kinase; MMP-9, matrix metalloproteinase-9; c-PARP, cleaved poly (ADP-ribose) polymerase; RLU, relative luciferase units. 

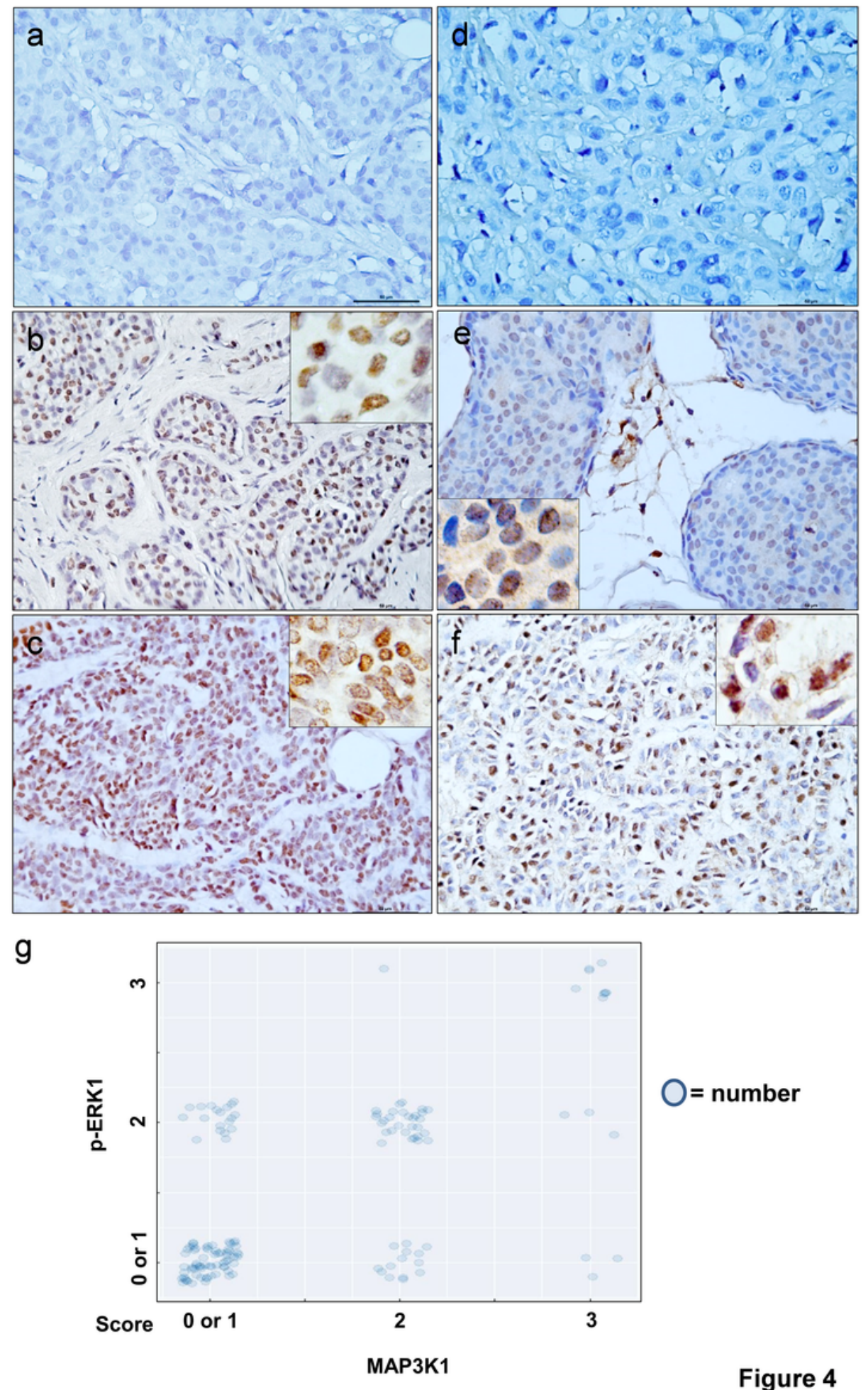

$\mathrm{O}=$ number

Figure 4

\section{Figure 4}

Expression of MAP3K1 and p-ERK in tumor cells of early-stage HR-positive, HER2-negative breast cancer patients. a Negative expression of MAP3K1 in tumor specimens of breast IDC. $b$ Representative images of moderate expression of MAP3K1 in tumor specimens of breast IDC (right upper inset 1000x). C Representative images of high expression of MAP3K1 in tumor specimens of breast IDC (right upper inset, 1000x). d Negative expression of p-ERK in tumor specimens of breast IDC. e Representative images 
of moderate expression of p-ERK in tumor specimens of breast IDC (left bottom inset 1000x) $f$ Representative images of high expression of p-ERK in tumor specimens of breast IDC (right upper inset, 1000x). $g$ The scatter plot showed the significant relation between $p$-ERK expression and MAP3K1 expression (Spearman's correlation, Correlation Coefficient $=0.538 ; p<0.001$ ). MAP3K1, mitogenactivated protein kinase kinase kinase 1; p-ERK, phospho-extracellular signal-regulated kinase; HR, hormone receptor; HER-2, human epidermal growth factor receptor 2; IDC, infiltrating ductal carcinoma.

a

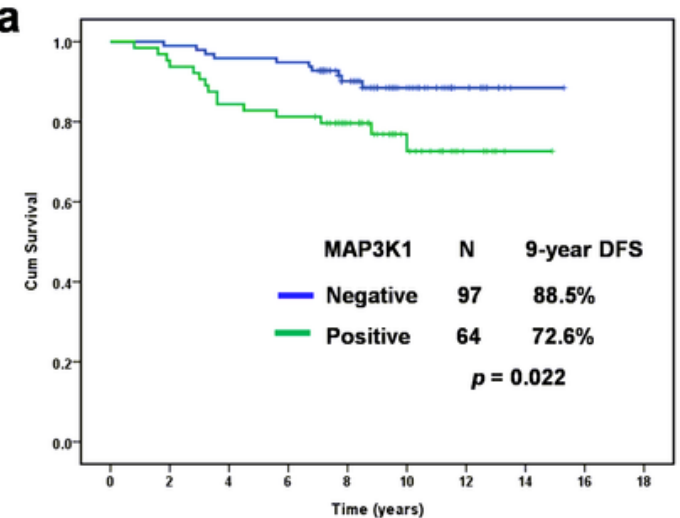

C

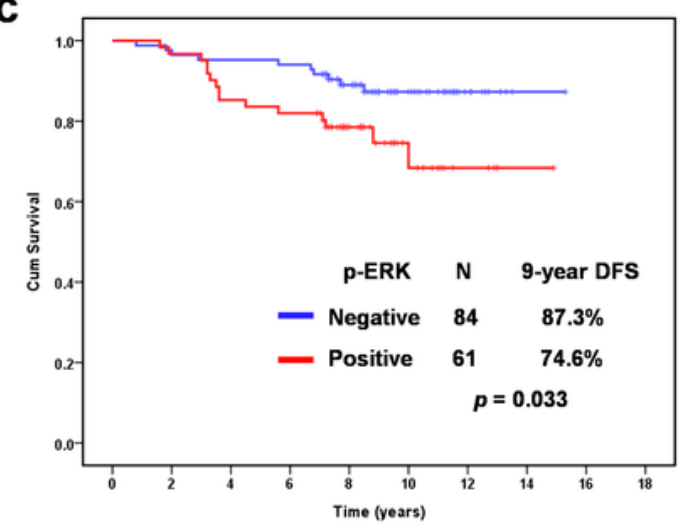

b

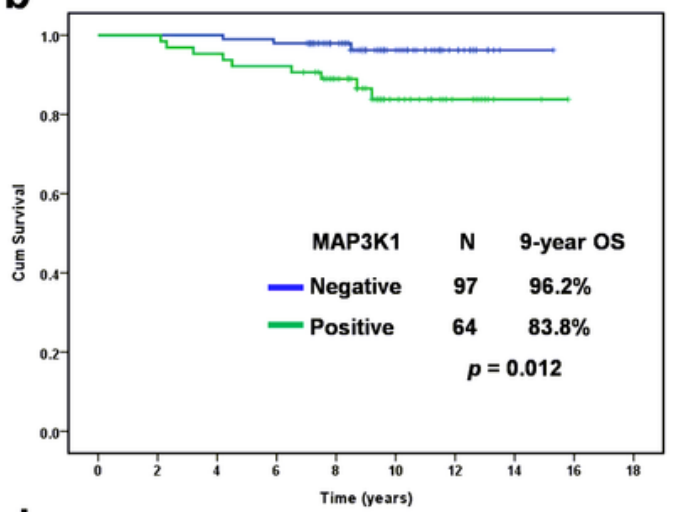

d

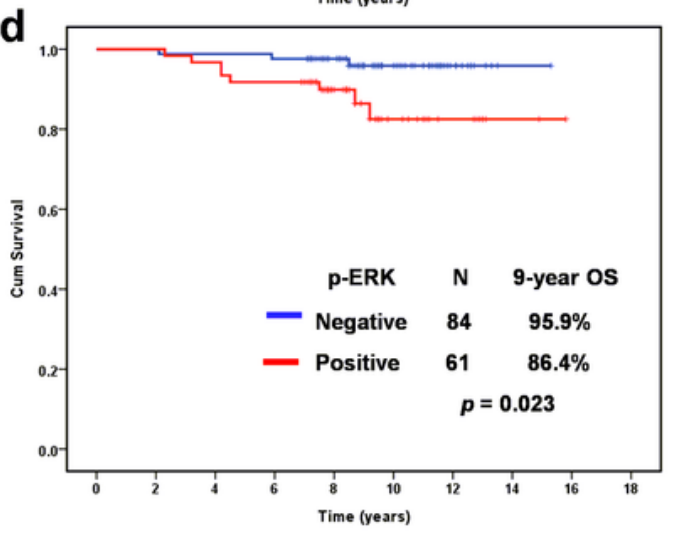

e

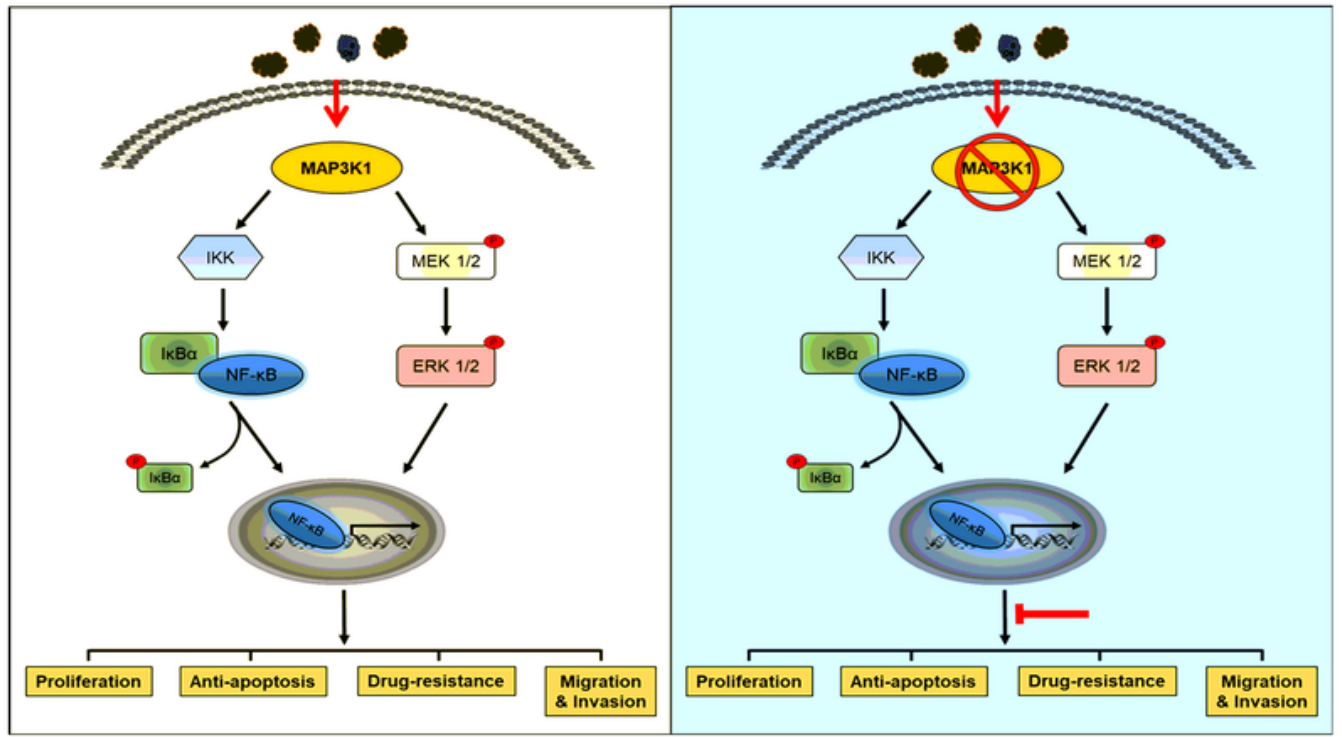

Figure 5

Figure 5 
Association between MAP3K1 expression or p-ERK expression in tumor cells and survival of early-stage HR-positive, HER2-negative breast cancer patients. a The DFS for all patients associated with the expression of MAP3K1. $b$ The OS for all patients associated with the expression of MAP3K1. c The DFS for all patients associated with the expression of $p$-ERK. $d$ The OS for all patients associated with the expression of p-ERK. e MAP3K1 promotes HR-positive, HER2-negative breast cancer cell proliferation, migration, invasion, and resistance to the drugs (docetaxel, doxorubicin, and tamoxifen) through activating ERK and NF-KB signaling; and inhibition of MAP3K1 attenuates tumor growth, migration and invasion, and enhances drugs sensitivities of this subtype of breast cancer through downregulation of ERK and NF-KB signaling. MAP3K1, mitogen-activated protein kinase kinase kinase 1; p-ERK, phosphoextracellular signal-regulated kinase; HR, hormone receptor; HER-2, human epidermal growth factor receptor 2; DFS, disease-free survival; OS, overall survival.

\section{Supplementary Files}

This is a list of supplementary files associated with this preprint. Click to download.

- Supplementaryinformation.docx

- Supplementaryinformation.docx

- SupplementalFigureS3.pdf

- SupplementalFigureS3.pdf

- SupplementalFig2S.pdf

- SupplementalFig2S.pdf

- SupplementalFlgureS1.pdf

- SupplementalFlgureS1.pdf

- SupplementaryMethodsMAP3k1.docx

- SupplementaryMethodsMAP3k1.docx 